\title{
Ausblick mit Markttrend
}

Welches Hotelkonzept passt zu welchem Standort? Die Frage ist ebenso einzelfallabhängig zu beantworten wie die Frage nach dem passenden Vertragstyp. Leider gibt es für beide Fragen keine Standardantwort. Chancen und Risiken müssen ausgewogen verteilt werden - dies ist zumindest das Petitum des beratenden Rechtsanwaltes ${ }^{1}$.

Wir erleben immer ausdifferenziertere Regelungen in den Betreiberverträgen zu Instandhaltungsklauseln, Mietsicherheit und deren einzelnen Bestandteilen und auch vertragliche Begrenzungs- bzw. Änderungsmodelle von Fixmieten zu Umsatzmieten etc. Ein allgemeiner und belastbar als solcher zu bezeichnender Markttrend kann hieraus aber nicht abgeleitet werden. Dies hat seinen Grund schlicht darin, dass jeder Mietvertrag bzw. jeder Pachtvertrag individuell auf den jeweiligen Match zwischen Immobilie und Betreiber zugeschnitten ist. Was man aber ablesen kann, ist ein moderater Anstieg in Eigentümerzuschüssen bei Developmentprojekten. So sind moderat erhöhte FF\&E-Zuschüsse zu sehen. Es werden darüber hinaus auch leicht erhöhte Pre-Opening-Fees bzw. Design-Fees oder längere mietfreie Zeiten vereinbart. Diese Anpassung dürfte ihre Gründe allerdings nicht im Verhältnis zwischen Eigentümer und Hotelier haben, sondern schlicht auf die speziellen Preissteigerungen in der Marktdynamik zurückzuführen sein.

\footnotetext{
${ }^{1}$ Nur ausgewogen verhandelte Verträge können letztlich bei Laufzeiten von über 20 bis 30 Jahren ein gedeihliches Miteinander und damit Renditen ermöglichen. Streit zwischen den Vertragsparteien kostet Kraft, Zeit (auch sog. management attention) und letztlich Geld.
} 